\title{
Screening the ability of natural feed ingredients to interfere with the adherence of enterotoxigenic Escherichia coli (ETEC) K88 to the porcine intestinal mucus
}

\author{
Gemma González-Ortiz ${ }^{1 *}$, José Francisco Pérez ${ }^{1}$, Rafael Gustavo Hermes ${ }^{1}$, Francesc Molist ${ }^{1}$, \\ Rufino Jiménez-Díaz ${ }^{2}$ and Susana María Martín-Orúe ${ }^{1}$ \\ ${ }^{1}$ Departament de Ciència Animal i dels Aliments, Servei de Nutrició i Benestar Animal (SNiBA), Universitat Autònoma de \\ Barcelona (UAB), 08193 Bellaterra, Barcelona, Spain \\ ${ }^{2}$ Departamento de Biotecnología de Alimentos, Instituto de la Grasa, Consejo Superior de Investigaciones Científicas (CSIC), \\ Avda. Padre Garcia Tejero, 4, 1078, 41012 Sevilla, Spain
}

(Submitted 5 May 2013 - Final revision received 5 August 2013 - Accepted 18 August 2013 - First published online 19 September 2013)

\section{Abstract}

The inhibition of the attachment of bacteria to the intestine by receptor analogues could be a novel approach to prevent enterotoxigenic Escherichia coli (ETEC) K88-induced diarrhoea in piglets. The objective of the present study was to screen the ability of different feed ingredients (FI) to bind to ETEC K88 (adhesion test, AT) and to block its attachment to the porcine intestinal mucus (blocking test, BT) using in vitro microtitration-based models. In the AT, wheat bran (WB), casein glycomacropeptide (CGMP) and exopolysaccharides exhibited the highest adhesion to ETEC K88 $(P<0 \cdot 001)$. In the BT, WB, CGMP and locust bean (LB) reduced the number of ETEC K88 attached to the intestinal mucus $(P<0.001)$. For WB and LB, fractionation based on their carbohydrate components was subsequently carried out, and each fraction was evaluated individually. None of the WB fractions reduced the adhesion of ETEC K88 to the mucus as did the original extract, suggesting that a protein or glycoprotein could be involved in the recognition process. With regard to the LB fractions, the water-extractable material reduced the adhesion of ETEC K88 $(P<0 \cdot 001)$ to the mucus similar to the original extract $(P<0 \cdot 001)$, indicating, in this case, that galactomannans or phenolic compounds could be responsible for the recognition process. In conclusion, among the FI screened, the soluble extracts obtained from WB, LB and CGMP exhibited the highest anti-adhesive properties against ETEC K88 in the BT. These results suggest that they may be good candidates to be included in diets of weaned piglets for the prevention of ETEC K88-induced diarrhoea.

Key words: Enterotoxigenic Escherichia coli K88: Natural feed ingredients: Antiadhesives: Porcine intestinal mucus: Piglets

Colibacillosis caused by the strains of enterotoxigenic Escherichia coli (ETEC) is a common diarrhoeic disease in neonatal and early weaned pigs ${ }^{(1)}$ and is the most important disease worldwide in the swine industry ${ }^{(2)}$. Specifically, ETEC K88 serotype, which expresses fimbrial adhesin F4, is the most prevalent serotype responsible for this disease. The susceptibility of piglets to ETEC K88 is inherited as an autosomal dominant trait and is determined by the expression of receptors on the enterocyte brush borders ${ }^{(3)}$. So, the recognition of the intestinal receptors by the bacterial fimbriae and the attachment of $E$. coli to the brush border of epithelial cells are considered as the primary requisites for the pathogenesis of colibacillosis. After attachment, ETEC K88 can also produce enterotoxins that induce water and electrolyte secretion into the intestinal lumen, resulting in dehydration and metabolic acidosis ${ }^{(4)}$.

Receptors for ETEC K88 fimbriae appear to be glycoconjugates, which are sparsely located on the mucosal surface of the small intestine of piglets, preferentially in the ileum ${ }^{(5)}$. Different antigenic variants, referred to as K88ab, K88ac and K88ad fimbriae, bind to their own set of receptors. Whereas the K88ab and K88ac adhesins preferentially bind to glycoproteins, the K88ad adhesin appears to bind to glycolipids ${ }^{(6)}$ In both cases, carbohydrates seem to play a key role in the binding of the receptors to ETEC K88 fimbrial adhesins ${ }^{(7)}$. In this sense, the importance of $\mathrm{N}$-acetylgalactosamine,

Abbreviations: AED1, alkali extraction after the first dialysis; AED2, alkali extraction after the second dialysis; BT, blocking test; cfu, colony-forming unit; CGMP, casein glycomacropeptide; EPS, exopolysaccharides; ETEC, enterotoxigenic Escherichia coli; FI, feed ingredient; LB, locust bean; LG, locust gum; MOS, mannan-oligosaccharides; OD, optical density; SBP, sugarbeet pulp; WB, wheat bran; WEM, water-extractable material.

*Corresponding author: G. González-Ortiz, fax +34935 811494, email gemma.gonzalez.ortiz@gmail.com 
fucosylated tetra- and pentasaccharides, GalNAc( $\beta 1-4)$ Galcontaining sequences, $\quad \beta$-galactose, $N$-acetyllactosamine (LacNAc) and phosphatidylethanolamine has been pointed out $^{(8)}$. Taking this into account, on the basis of their glycoside composition, the incorporation of some receptor analogues in the diet would be a practical strategy to reduce the number of some intestinal pathogens ${ }^{(9)}$, including that of ETEC K88 ${ }^{(10)}$. Until now, numerous reports on the ability of natural feed ingredients (FI) to bind to or block the attachment of ETEC K88 to the intestinal mucosa based on their complex carbohydrate composition have been published ${ }^{(11-14)}$. Some vegetables have been proposed as attractive alternatives to antibiotics for swine production ${ }^{(15)}$. Other natural products, such as casein glycomacropeptide (CGMP) ${ }^{(5,9)}$ and microbial by-products, such as exopolysaccharides (EPS) and mannanoligosaccharides (MOS), have also been suggested to act as enteropathogen antiadhesives ${ }^{(16-19)}$. However, no evidence about the specific interaction between these ingredients and ETEC K88 regarding their ability to block the adhesion of ETEC K88 to the intestinal mucus under in vitro conditions has been reported by solely evaluating their interactions.

The objective of the present study was to make an in vitro screening comparison of the ability of different compounds to bind to ETEC K88 and to block or reduce its attachment to the intestinal mucus using microtitration-based adhesion tests.

\section{Materials and methods}

\section{Animals and mucus isolation}

The present experiment received previous approval from the Animal Protocol Review Committee of the Universitat Autònoma de Barcelona (no. 689). The treatment, management, housing, husbandry and slaughtering conditions conformed to the European Union Guidelines (The Council of the European Communities, registered under no. 11GCE007-R).

For the present experiment, five weaned piglets ( $28 \mathrm{~d}$ of age) from a commercial farm were selected on the basis of their genotype for susceptibility to ETEC K88 using a DNA marker-based test $^{(3)}$, allowing for genomic characterisation for the presence of $\mathrm{F} 4$ receptors in the intestinal epithelium. The piglets were maintained at the experimental facilities of the Universitat Autònoma de Barcelona. The piglets were fed a commercial feed treated with colistin for five consecutive days (Coliplus ${ }^{\circledR}$ Solution, Divasa Farmavic SA; $102500 \mathrm{UI} / \mathrm{kg}$ ( $4.22 \mathrm{mg} / \mathrm{kg}$ ) of body weight) and complementarily treated by intramuscular administration (Trimixin, S.P. Veterinaria SA) to reduce the microbial load in their gastrointestinal tract ${ }^{(5)}$. The piglets were killed by intravenous sodium pentobarbital overdosing $(200 \mathrm{mg} / \mathrm{kg}$ body weight), and the abdomen was immediately cut opened. The ileum was extracted and immersed in the binding buffer (3.84 mm-NaH $\mathrm{PO}_{4}, 6.16 \mathrm{~mm}-\mathrm{Na}_{2} \mathrm{HPO}_{4}$ and $0.15 \mathrm{~m} \mathrm{NaCl}, \mathrm{pH}$ 7.2). After that, sections were split along the mesenteric border and washed with sterile PBS. The intestinal mucus was recovered following the Fang et al. ${ }^{(20)}$ procedures. Briefly, the mucus was collected by gentle scraping with a glass slide and was then transferred into $20 \mathrm{ml}$ of the binding buffer. All processes were carried out in an ice-cold bath. The scrapings of all the piglets were pooled, mixed and centrifuged at $10000 \mathbf{g}$ at $4^{\circ} \mathrm{C}$ for $15 \mathrm{~min}$ to remove particulate material. The aliquots of supernatants containing the ileal mucus were stored at $-80^{\circ} \mathrm{C}$ until use. Before its utilisation in the in vitro tests, the ileal mucus was analysed for protein concentration and for the absence of any indigenous microbial contamination by monitoring the optical density (OD) of its culture in Luria broth $\left(650 \mathrm{~nm}\right.$, every $10 \mathrm{~min}$ for $12 \mathrm{~h}$ at $\left.37^{\circ} \mathrm{C}\right)$. Before each blocking test (BT), mucus was thawed and diluted 1:2 in sterile PBS to prepare the coating suspension well.

\section{Feed ingredient extraction}

The FI evaluated in the present study are listed out in Table 1, including ingredients of vegetable origin, a dairy protein and three microbial by-products.

All the ingredients were prepared following the protocol described by Becker et al. ${ }^{(21)}$. Briefly, coarse ingredients, such as wheat bran (WB), soyabean hulls and sugarbeet pulp (SBP), were finely ground in an analytical grinder. All the products were suspended in PBS at a solid:liquid ratio of 1:100 (w/v). Subsequently, the suspensions were sonicated three times for $30 \mathrm{~s}$ each (Unheated Ultrasonic Bath, JP Selecta) and then centrifuged at $460 \mathrm{~g}$ for $5 \mathrm{~min}$ (Mikro 220R, Hettich Zentrifugen). The supernatants were stored at $-20^{\circ} \mathrm{C}$ until used in the in vitro tests.

\section{Wheat bran and locust bean fractionation}

WB and locust bean (LB), which are ingredients rich in fibre and NSP, were also fractionated according to the Maes \& Delcour ${ }^{(22)}$ procedures, which characterise different water-extractable and water-unextractable fibrous fractions from WB. Of each FI, three different fractions were obtained. The water-extractable material (WEM) was the first fraction obtained after enzymatic digestion $\left(\alpha\right.$-amylase $\left(90^{\circ} \mathrm{C}-30 \mathrm{~min}\right)$, protease $\left(55^{\circ} \mathrm{C}-4 \mathrm{~h}\right)$ and amyloglucosidase $\left(60^{\circ} \mathrm{C}-\right.$ overnight $)$, which in the case of $\mathrm{WB}$, according to the authors, mainly comprises more or less $50 \%$ of the total of non-cellulosic sugars (glucose, xylose and arabinose) and high protein content (33\%), but little arabinoxylan content $(10 \%)^{(22)}$. The first alkali treatment of the cellulosic residue led to a fraction, designated as AED1, and the second alkali treatment to the fraction AED2. During the dialysis step, more than $90 \%$ of the ash content and $30 \%$ of the proteins were removed. The authors reported that these two fractions (AED1 and AED2) have similar monosaccharide composition, and in both extracts, above $90 \%$ are arabinoxylans when referring to WB samples ${ }^{(22)}$. Although Maes \& Delcour ${ }^{(22)}$ applied this fractionation only to $\mathrm{WB}$, in the present study, we also applied this procedure to LB looking for a similar physico-chemical fractionation of NSP. The three fractions obtained from WB and LB were included in the in vitro adhesion and BT.

\section{Escherichia coli strains}

In the present experiment, two different $E$. coli strains were used. Of these, one was an ETEC K88 strain isolated during 
Table 1. Feed ingredients used in the adhesion and blocking tests, along with the feed ingredient abbreviation, the provider company and the country of origin

\begin{tabular}{llll}
\hline Products & Abbreviation & Provider company & Country of origin \\
\hline Controls & & & \\
PBS & PBS & Sigma & Spain \\
$\begin{array}{l}\text { D-Mannose } \\
\text { Products of vegetable origin }\end{array}$ & MAN & Sigma & Spain \\
Wheat bran & WB & Local mill & Spain \\
Soyabean hulls & SO & Local mill & Spain \\
Sugarbeet pulp & SBP & Local mill & Spain \\
Locust bean* & LB & Armengol, S.A. & Spain \\
Locust gum & LG & Polygal, S.A. & Switzerland \\
Guar gum & GG & Polygal, S.A. & Switzerland \\
Cranberry extract & CRA & Cran Max, S.A. & United States \\
Fructo-oligosaccharides & FOS & Beghin Meiji, S.A. & France \\
Inulin & INU & Orafti, S.A. & Belgium \\
Dairy products & & & \\
Casein glycomacropeptide & CGMP & Arla Foods, S.A. & Denmark \\
Microbial products & & & \\
Exopolysaccharides† & EPS & IG-CSIC $¥$ & Spain \\
Mannan-oligosaccharides & MOS & Alltech, S.A. & Spain \\
Fermented extract from Aspergillus oryzae & AO & Molimen, S.L. & Spain \\
\hline
\end{tabular}

* Product obtained from the carob tree (Ceratonia siliqua) including a meal mixture of carob pods and carob seeds.

† Exopolysaccharides obtained from olive fermentation brines.

$\ddagger$ Instituto de la Grasa - Consejo Superior de Investigaciones Científicas (Sevilla, Spain).

a colibacillosis outbreak in Spain ${ }^{(23)}$, serotype (O149:K91:H10 (K-88)/LT-I/STb), which was generously provided by the E. coli Reference Laboratory, Veterinary Faculty of Santiago de Compostela. The other was a non-fimbriated E. coli (F4-, F6-, F18-, LT1-, ST1-, ST2 +, Stx2e-) isolated from the faeces of a post-weaning piglet and kindly donated by the Departament de Sanitat i d'Anatomia Animals of the Universitat Autònoma de Barcelona. ETEC K88 was cultured in unshaken Luria broth at $37^{\circ} \mathrm{C}^{(24)}$, while the non-fimbriated E. coli was cultured in shaking media. Bacteria were serially cultured every $48 \mathrm{~h}$, at least three times.

Bacterial cells were collected by centrifugation of $15 \mathrm{ml}$ of an overnight culture $(1700 \mathbf{g}, 5 \mathrm{~min}$; Hettich Zentrifugen Mikro 220R). The supernatants were removed, and PBS buffer was added to the cell pellet to achieve an OD of the bacterial suspension of $1(650 \mathrm{~nm})$, which was used in the adhesion test (approximately log 9-8.5 colony-forming units $(\mathrm{cfu}) / \mathrm{ml})$. For the BT, bacterial suspensions were serially diluted to $6 \cdot 5-7 \log \mathrm{cfu} / \mathrm{ml}$.

\section{Adhesion test}

The ability of the different FI to adhere to ETEC K88 was determined using an adaptation of the in vitro AT described by Becker et al. ${ }^{(21)}$. The procedure involves the use of ninety-six-well high-binding polystyrene microtitration plates (Microlon F plate 655 092; Greiner Bio-One BV). Briefly, after overnight incubation at $4^{\circ} \mathrm{C}$ with $300 \mu \mathrm{l}$ of the FI extracts, the plates were washed with sterile PBS to remove nonbinding material. Afterwards, the non-specific adhesion sites were blocked by incubating the plates with $1 \%$ bovine serum albumin and $0.5 \%$ sodium azide in PBS $(\mathrm{w} / \mathrm{v})$ at $4{ }^{\circ} \mathrm{C}$ for $1 \mathrm{~h}$. Thereafter, the plates were washed twice with sterile PBS, and then $300 \mu$ l of the bacterial suspensions (ETEC K88 or non-fimbriated $E$. coli) were added. The plates were incubated for $30 \mathrm{~min}$ at room temperature and washed three times with sterile PBS to remove the non-attached bacteria. Finally, $300 \mu \mathrm{l}$ of sterile Luria broth were added, and the sigmoidal growth of bacteria was measured using a microplate reader (Spectramax 384 Plus, Molecular Devices Corporation) at $37^{\circ} \mathrm{C}$, following the protocol described by Becker et al. ${ }^{(21)}$ Bacterial growth was monitored as OD at a wavelength of $650 \mathrm{~nm}$ at intervals of $10 \mathrm{~min}$ for $12 \mathrm{~h}$. All the readings were taken in two independent assays and in triplicate per trial.

\section{Blocking test}

The BT was carried out by adapting the methodology described above. Briefly, $300 \mu$ l per well of the mucus suspensions were pipetted into the flat-bottomed ninety-six wells of high-binding polystyrene microtitration plates and incubated overnight at $4^{\circ} \mathrm{C}$. The plates were washed with $300 \mu$ l of PBS to remove non-binding material. To avoid non-specific adhesion, the wells were treated with $350 \mu \mathrm{l}$ of a mixture containing $1 \%$ bovine serum albumin in PBS and $0.5 \%$ sodium azide at $4^{\circ} \mathrm{C}$ for $1 \mathrm{~h}$. Subsequently, two washing steps were carried out using $300 \mu \mathrm{l}$ of PBS. To $500 \mu \mathrm{l}$ of each tested FI extract (1\%), $500 \mu$ l of each bacterial suspension were added separately and incubated at $37^{\circ} \mathrm{C}$ for $30 \mathrm{~min}$. After that, $300 \mu \mathrm{l}$ of the co-incubated mixtures were added, in triplicate, to the wells of the microtitration plates and were allowed to adhere to the mucus at room temperature for 30 min. Afterwards, an equal number of washing steps and medium addition and bacterial growth monitoring procedures were carried out as in the in vitro AT protocol described above.

Additionally, the absence of any microbial growth in the FI extracts probably interfering with the test was evaluated by 
including controls of each extract co-incubated with PBS instead of with bacteria. To exclude the presence of antimicrobial compounds or nutrients in the FI extracts that could modify the number of viable bacteria after co-incubation, microbial counts in Luria agar plates were also conducted after the co-incubation step $\left(30 \mathrm{~min}\right.$ at $37^{\circ} \mathrm{C}$ and $30 \mathrm{~min}$ at room temperature). No differences related to PBS were detected. The supernatants of FI that exhibited the highest specific blocking properties (WB, CGMP and LB) were also tested at $0.2,0.4,0.6$ and $0.8 \%(\mathrm{w} / \mathrm{v})$ in different dosageresponse $\mathrm{BT}$.

\section{Bacterial counts and $\mathrm{t}_{\mathrm{OD}=0.05}$ correlations}

In trying to translate the OD values $\left(t_{\mathrm{OD}=0.05}\right)$ to cfu per well initially attached to the FI extracts (in the AT) or mucus (in the BT), an assay was carried out with ETEC K88 and the non-fimbriated E. coli strains. Both bacteria were serially diluted in Luria broth medium. The cfu were determined after serial dilutions in PBS, plating on Luria agar and incubation at $37^{\circ} \mathrm{C}$ for $48 \mathrm{~h}$. At the same time, three replicates of each bacteria and dilution were incubated, adding $300 \mu \mathrm{l}$ of each dilution per well to the microtitration plates. The growth characteristics were determined at $37^{\circ} \mathrm{C}$ for $18 \mathrm{~h}$ using a microplate reader (SPECTRAmax 384 Plus, Molecular Devices Corporation) as described above in the AT and BT protocols. The $t_{\mathrm{OD}=0.05}(\mathrm{~h})$ and cfu values obtained for each dilution were used to fit the following linear models: $y=-1.6371 x+13.543\left(R^{2} 0.994\right)$ for ETEC K88 and $y=-1.2875 x+11.999\left(R^{2} 0.996\right)$ for the non-fimbriated $E$. coli, where ' $y$ ' corresponds to $t_{\mathrm{OD}=0.05}$ and ' $x$ ' to the log of cfu per well.

\section{Statistical analyses}

All the statistical analyses were carried out using SAS 9.2 (SAS, Inc.). The OD data from the AT and the BT were processed by a non-linear regression analysis using the non-linear P-NLIN (Gauss-Newton method) procedure (SAS 9.2, SAS, Inc.) following the equations described previously ${ }^{(21)}$. From the time when the bacterial growth reached an OD of 0.05 $\left(t_{\mathrm{OD}=0-05}, \mathrm{~h}\right)$, the $\log$ cfu were calculated for each FI using the previously described linear models. Significant differences in the log cfu among the FI and between bacterial strains were determined using ANOVA. Linear, quadratic and cubic contrasts were conducted to analyse the dose response of each FI. Differences between the means were tested using the Tukey-Kramer adjustment for multiple comparisons.

\section{Results}

\section{In vitro adhesion test}

Table 2 summarises the ability of different FI to adhere to ETEC K88 and non-fimbriated E. coli as the number of bacteria attached to each well (log cfu per well). For most of the FI extracts, higher attachment was observed for ETEC K88 than for the non-fimbriated $E$. coli, indicating that fimbriae play an important role in bacterial adherence. The results indicated three different levels of adhesion to ETEC K88. A group including WB, CGMP and EPS exhibited the highest adhesion, with more than $7 \log$ ETEC K88 cfu per well. Soyabean hull, locust gum (LG), guar gum and MOS had values between 7 and $6 \log$ ETEC K88 cfu per well. Finally, the remaining FI, LB, fructo-oligosaccharides, D-mannose, inulin, fermented

Table 2. Number of bacteria (log colony-forming units (cfu) per well) attached to wells coated with different feed ingredient extracts in the adhesion test ${ }^{*}$

\begin{tabular}{|c|c|c|c|c|}
\hline \multirow[b]{2}{*}{ Feed ingredient extracts $†$} & \multicolumn{4}{|c|}{ Incubated bacteria } \\
\hline & ETEC K88 & Non-fimbriated E. coli & SEM & E. coli type $(P)$ \\
\hline PBS & $5 \cdot 42^{\mathrm{d}, \mathrm{e}}$ & $6 \cdot 26^{a, b}$ & 0.207 & 0.008 \\
\hline D-Mannose & $5 \cdot 29^{d, e, f}$ & $5 \cdot 43^{\mathrm{c}, \mathrm{d}, \mathrm{e}}$ & 0.114 & 0.203 \\
\hline Wheat bran & $7 \cdot 01^{a}$ & $5 \cdot 69^{\mathrm{b}, \mathrm{c}}$ & 0.332 & 0.008 \\
\hline Soyabean hulls & $6 \cdot 11^{\mathrm{b}, \mathrm{c}}$ & $5 \cdot 58^{\mathrm{c}, \mathrm{d}}$ & $0 \cdot 140$ & 0.010 \\
\hline Sugarbeet pulp & $5 \cdot 05^{f}$ & $5 \cdot 28^{c, d, e, f}$ & 0.152 & 0.141 \\
\hline Locust bean & $5 \cdot 61^{d}$ & $5 \cdot 26^{c, d, e, f}$ & $0 \cdot 107$ & 0.016 \\
\hline Locust gum & $6 \cdot 35^{b}$ & $6 \cdot 48^{\mathrm{a}}$ & $0 \cdot 122$ & 0.257 \\
\hline Guar gum & $6 \cdot 00^{c}$ & $4.52^{\mathrm{g}}$ & $0 \cdot 172$ & 0.010 \\
\hline Cranberry & $5 \cdot 00^{f}$ & $4 \cdot 69^{f, g}$ & 0.091 & 0.015 \\
\hline Fructo-oligosaccharides & $5 \cdot 34^{\mathrm{d}, \mathrm{e}, \mathrm{f}}$ & $4 \cdot 84^{\mathrm{f}, \mathrm{g}}$ & 0.085 & 0.002 \\
\hline Inulin & $5 \cdot 00^{f}$ & $4.90^{\mathrm{e}, \mathrm{f}, \mathrm{g}}$ & $0 \cdot 103$ & 0.291 \\
\hline Casein glycomacropeptide & $7 \cdot 15^{\mathrm{a}}$ & $5 \cdot 03^{\mathrm{d}, e, f, g}$ & $0 \cdot 107$ & $<0.001$ \\
\hline Exopolysaccharides & $7 \cdot 18^{\mathrm{a}}$ & $5 \cdot 78^{\mathrm{b}, \mathrm{c}}$ & $0 \cdot 181$ & 0.001 \\
\hline Mannan-oligosaccharides & $6 \cdot 22^{\mathrm{b}, \mathrm{c}}$ & $4 \cdot 53^{\mathrm{g}}$ & $0 \cdot 138$ & $<0.001$ \\
\hline Fermented extract from Aspergillus oryzae & $5 \cdot 15^{\mathrm{e}, \mathrm{f}}$ & $4 \cdot 80^{f, g}$ & $0 \cdot 153$ & 0.050 \\
\hline SEM & 0.113 & 0.193 & & \\
\hline Feed ingredients $(P)$ & $<0.001$ & $<0.001$ & & \\
\hline
\end{tabular}

ETEC, enterotoxigenic Escherichia coli.

a,b,c,d,e,f,g Values with unlike superscript letters within a column were significantly different among the feed ingredients $(P<0.001)$.

* Each value (log cfu per well) was obtained from the average of three replicates in, at least, two independent in vitro assays according to the fitted equations.

†After extraction, all the feed ingredient extracts were tested at $1 \%(\mathrm{w} / \mathrm{v})$. 
extract from Aspergillus oryzae, SBP and cranberry, yielded results similar to those of the negative control (PBS).

\section{In vitro blocking test}

Table 3 summarises the number of bacteria attached to the intestinal mucus after co-incubation with the different ingredient extracts (log cfu per well). In this case, a lower number of bacterial cells is associated with a higher blocking activity of the compounds. The results indicated that five ingredients, WB, LB, LG, guar gum and CGMP, significantly $(P<0.05)$ decreased the attachment of ETEC K88 to the mucus, when compared with PBS. By contrast, none of these ingredients was able to significantly decrease the number of the nonfimbriated $E$. coli attached to the mucus, thus demonstrating their specificity to ETEC K88. Among the FI, WB, LB and CGMP exhibited the highest effects with reductions of bacterial numbers by more than one log unit.

The dose-response assay with the WB, CGMP and LB extracts revealed a significant linear response $(P<0.001)$ among the dosages evaluated for the three ingredients (Fig. 1). Nonetheless, the quadratic and cubic contrasts were also significant for LB $(P<0.001)$ and CGMP $(P<0.05)$, respectively.

\section{Fractionation of the carbohydrate components of} wheat bran and locust bean

Carbohydrate fractions obtained from the two vegetable ingredients that exhibited the highest blocking activity (WB and LB) were evaluated in relation to their adhesive (Fig. 2) and antiadhesive (Fig. 3) properties. All the WB fractions (WEM and AED1 and AED2) exhibited lower adhesive properties than did the sonicated WB extract, while the adhesive property of the AED2 fraction was not significantly different from that of PBS (Fig. 2). With regard to $\mathrm{LB}$, neither the sonicated LB extract nor any of the LB fractions exhibited any relevant ability to adhere to ETEC K88.

The ability of these WB and LB fractions to block the attachment of ETEC K88 to the intestinal mucus is presented in Fig. 3. The WB fractions (WEM, AED1 and AED2) did not have the same ability to block the attachment of ETEC K88 as did the sonicated WB extract at $1 \%$. With regard to $\mathrm{LB}$, the sonicated extract, together with the LB WEM fraction, demonstrated a similar ability to block the attachment of ETEC K88. However, the AED1 and AED2 fractions did not exhibit anti-adhesive properties.

\section{Discussion}

Using two simple in vitro methods, the present study shows differences among FI regarding their ability to bind to ETEC K88 and to interfere with its attachment to the intestinal mucus of piglets. These adhesive and blocking activities, when they occurred, were specific for the ETEC K88 strain but not for the non-fimbriated $E$. coli, thus confirming the role of fimbria $\mathrm{F} 4$ in the adhesion of the bacteria to different substrates. Among the FI, WB, CGMP and EPS exhibited the highest binding capacity for ETEC K88. WB and CGMP, together with LB, also exhibited the highest blocking activity in the in vitro blocking assay.

\section{Casein glycomacropeptide}

The ability of CGMP to block the adhesion of ETEC K88 to the ileal mucus showed a positive linear and cubic dose response

Table 3. Number of bacteria (log colony-forming unit (cfu) per well) that attached to the natural mucus after being co-incubated with different feed ingredient extracts tested in the blocking test ${ }^{\star}$

\begin{tabular}{|c|c|c|c|c|}
\hline \multirow[b]{2}{*}{ Feed ingredient extracts $\dagger$} & \multicolumn{4}{|c|}{ Incubated bacteria } \\
\hline & ETEC K88 & Non-fimbriated E. coli & SEM & E. coli type $(P)$ \\
\hline PBS & $5 \cdot 13^{\mathrm{b}, \mathrm{c}, \mathrm{d}}$ & $5 \cdot 03^{\mathrm{a}, \mathrm{b}, \mathrm{c}}$ & 0.194 & 0.558 \\
\hline D-Mannose & $5 \cdot 60^{\mathrm{a}}$ & $4.93^{\mathrm{b}, \mathrm{c}}$ & 0.050 & $<0.001$ \\
\hline Wheat bran & $3 \cdot 87^{f, g}$ & $5 \cdot 19^{a, b}$ & 0.002 & $<0.001$ \\
\hline Soyabean hulls & $5 \cdot 10^{\mathrm{c}, \mathrm{d}}$ & $5.46^{\mathrm{a}}$ & 0.157 & 0.048 \\
\hline Sugarbeet pulp & $5 \cdot 35^{\mathrm{a}, \mathrm{b}, \mathrm{c}}$ & $4.94^{\mathrm{b}, \mathrm{c}}$ & 0.175 & 0.045 \\
\hline Locust bean & $3 \cdot 90^{f, g}$ & $5 \cdot 24^{\mathrm{a}, \mathrm{b}}$ & 0.152 & $<0.001$ \\
\hline Locust gum & $4.66^{\mathrm{e}}$ & $4 \cdot 78^{\mathrm{b}, \mathrm{c}, \mathrm{d}, \mathrm{e}}$ & 0.063 & 0.075 \\
\hline Guar gum & $4 \cdot 12^{f}$ & $4 \cdot 77^{\mathrm{b}, \mathrm{c}, \mathrm{d}, \mathrm{e}}$ & 0.134 & 0.004 \\
\hline Cranberry & $4 \cdot 88^{\mathrm{d}, \mathrm{e}}$ & $5.03^{a, b, c}$ & 0.032 & 0.364 \\
\hline Fructo-oligosaccharides & $5.06^{\mathrm{b}, \mathrm{c}, \mathrm{d}, \mathrm{e}}$ & $4 \cdot 61^{\mathrm{c}, \mathrm{d}, \mathrm{e}}$ & 0.050 & $<0.001$ \\
\hline Inulin & $5.03^{\mathrm{c}, \mathrm{d}, \mathrm{e}}$ & $4 \cdot 41^{\mathrm{d}, \mathrm{e}}$ & $0 \cdot 171$ & 0.012 \\
\hline Casein glycomacropeptide & $3 \cdot 70^{\mathrm{g}}$ & $4 \cdot 63^{\mathrm{c}, \mathrm{d}, \mathrm{e}}$ & 0.046 & $<0.001$ \\
\hline Exopolysaccharides & $4 \cdot 77^{\mathrm{d}, \mathrm{e}}$ & $4 \cdot 38^{\mathrm{c}, \mathrm{d}, \mathrm{e}}$ & 0.309 & 0.194 \\
\hline Mannan-oligosaccharides & $5 \cdot 48^{a, b}$ & $4 \cdot 90^{\mathrm{b}, \mathrm{c}, \mathrm{d}}$ & 0.099 & 0.002 \\
\hline Fermented extract from Aspergillus oryzae & $5 \cdot 51^{a, b}$ & $5 \cdot 04^{\mathrm{a}, \mathrm{b}, \mathrm{c}}$ & 0.204 & 0.049 \\
\hline SEM & 0.136 & 0.169 & & \\
\hline Feed ingredients $(P)$ & $<0.001$ & $<0.001$ & & \\
\hline
\end{tabular}

ETEC, enterotoxigenic Escherichia coli.

a,b,c,d,e,f,g Mean values with unlike superscript letters within a column were significantly different among the feed ingredients $(P<0.001)$. * Each value (log cfu per well) was obtained from the average of three replicates in, at least, two independent in vitro assays according to the fitted equations.

† After extraction, all the feed ingredient extracts were tested at $1 \%(\mathrm{w} / \mathrm{v})$ 

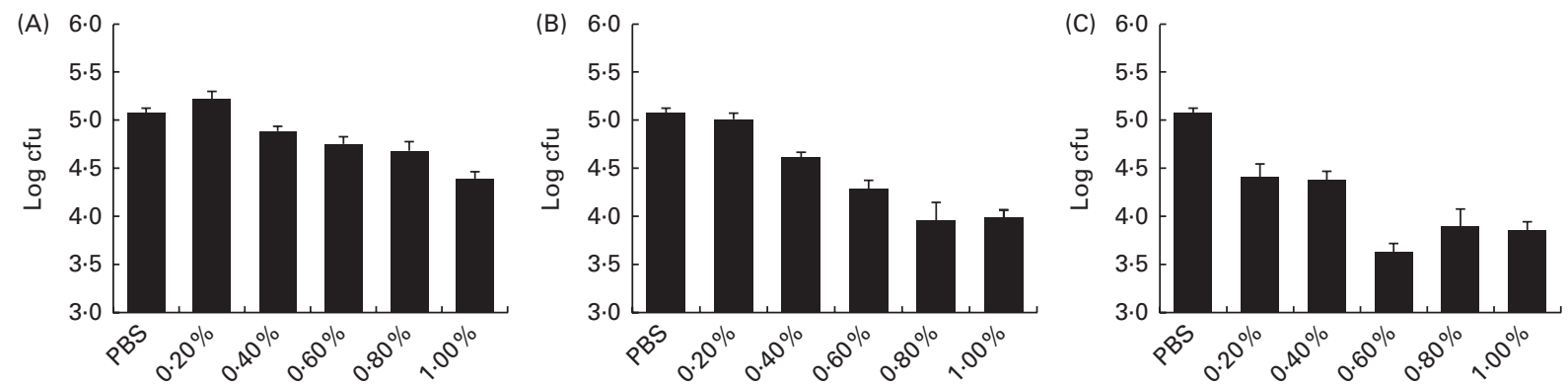

Fig. 1. Dose-response relationships of the ability of the (A) wheat bran, (B) casein glycomacropeptide and (C) locust bean extracts to block the attachment of enterotoxigenic Escherichia coli K88 to the natural ileal mucus. Log colony-forming units (cfu): number of bacteria attached to the natural ileal mucus that were not blocked by the feed ingredients in the blocking test. The lower the log cfu counts, the higher the adhesion-blocking ability. Linear ((A) $P<0.001$; (B) $P<0.001$; (C) $P<0.001$ ), quadratic ((A) $P=0.095$; (B) $P=0.399$; (C) $P<0.001$ ) and cubic ((A) $P=0.354$; (B) $P=0.020$; (C) $P=0.767$ ) contrasts were conducted to analyse the dose response of each feed ingredient. Data were obtained from the experiments carried out in triplicate in two independent assays. Values are means, with their standard errors represented by vertical bars.

in the range of $0 \cdot 2-1 \%$. Brody ${ }^{(25)}$ reviewed the evidence that CGMP obtained from bovine milk binds to $E$. coli toxins, inhibits bacterial and viral adhesion, promotes bifidobacterial growth and modulates the immune system response of the animals. Moreover, Nakajima et $a l^{(26)}$ and Malkoski et $a l^{(27)}$ reported the anti-adhesive properties of CGMP against E. coli, arguing for the presence of glycoprotein structures. CGMP contains three glycosylation sites with a heterogeneous array of glycans, based on a core of $\mathrm{Gal} \beta(1 \rightarrow 3)$ GalNAc- and $\operatorname{NeuAc}(2 \rightarrow 5)$ Gal-, which may act as potential receptor analogues ${ }^{(28,29)}$. In this sense, searching for new theranostic systems, the specific recognition of CGMP to ETEC K88, instead of to the non-fimbriated $E$. coli, was determined using chronoamperometric measurements ${ }^{(30)}$. In piglets, CGMP was able to reduce in vitro the attachment of ETEC K88 to porcine intestinal epithelial cells (IPEC-J2) ${ }^{(14)}$ and also to reduce in vivo the incidence of diarrhoea and the attachment of $E$. coli to intestinal villi ${ }^{(5)}$.

\section{Wheat bran}

WB is the by-product of the wheat milling industry. It is the outermost covering of wheat grain, which is rich in carbohydrates ( $40 \%$ of NSP and $34 \%$ of starch) and protein $(12 \%)^{(31)}$. In human medicine, WB has been proposed as a cholesterol reducer and for the prevention of certain gastrointestinal cancers ${ }^{(32)}$. To our knowledge, the pathogenic anti-adhesive properties of WB have only been suggested in swine nutrition ${ }^{(14,33-35)}$, which can be confirmed by the results obtained by our research group.

The WB extract yielded positive results in both the adhesion and blocking assays. In addition, a significant linear dose response was demonstrated. Other in vivo experiments carried out in piglets orally challenged with ETEC K88 also showed that the dietary inclusion of WB reduced the incidence of diarrhoea and the attachment of $E$. coli to the ileal mucosa ${ }^{(34)}$. These results are also in agreement with other findings ${ }^{(33,35)}$, reporting that $\mathrm{WB}$ in the diet reduces the number of ubiquitous $E$. coli in the intestinal tract. Moreover, the ability of the WB soluble extract to block the adhesion of ETEC K88 to IPEC-J2 has also been demonstrated ${ }^{(14)}$.

The WEM did not exhibit the same ability as did the sonicated WB extract to adhere to ETEC K88. The alkaline extracts, AED1 and AED2, did not exhibit a higher adhesion capacity compared with the whole WB extract either. A similar response was observed in the $\mathrm{BT}$, in which none of the fractions exhibited the same blocking ability as did the sonicated WB extract. Both the AED1 and AED2 fractions have been reported to contain xylose (40\%) and arabinose (33\%) as the main monosaccharides ${ }^{(22)}$. The failure of these fractions
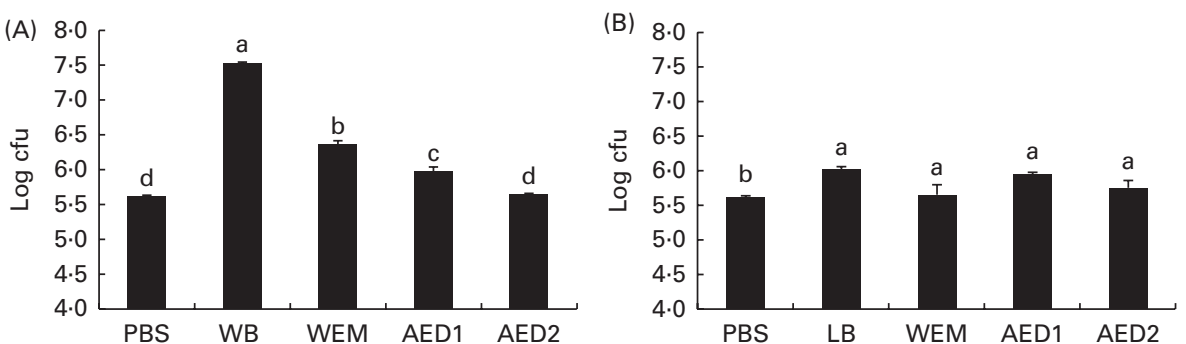

Fig. 2. Number of enterotoxigenic Escherichia coli K88 attached to wells (log colony-forming units (cfu) per well) coated with the different fractions obtained after the digestion process of (A) wheat bran (WB) and (B) locust bean (LB) in the adhesion test. WEM, water-extractable material after enzymatic digestion ( $\alpha$-amylase, protease and amyloglucosidase) and dialysis; AED1, fraction obtained after the first alkali treatment of the cellulosic residue; AED2, fraction obtained after the second alkali treatment. The higher the log cfu counts, the higher the adhesion ability. Values are means, with their standard errors represented by vertical bars. ${ }^{a, b, c, d}$ Mean values with unlike letters were significantly different between the fractions $(P<0.05)$. Data were obtained from the experiments carried out in triplicate in two independent assays. 

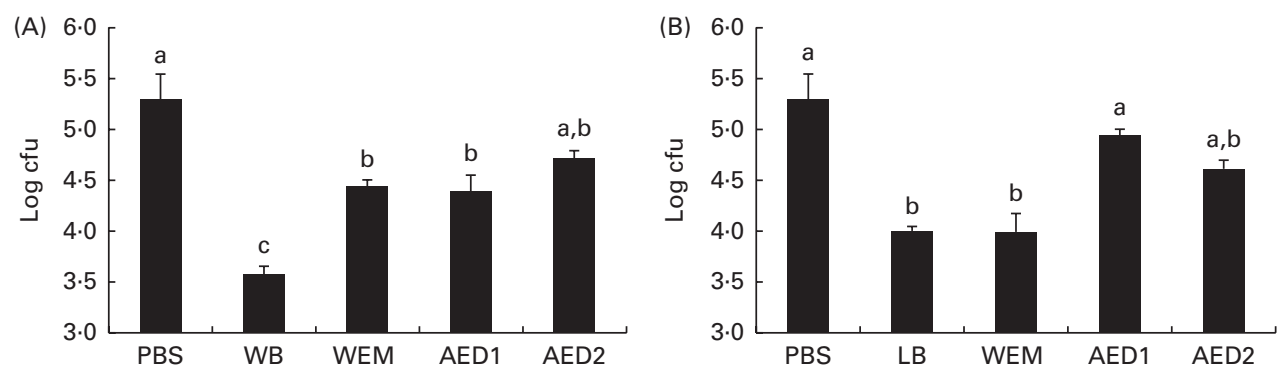

Fig. 3. Number of enterotoxigenic Escherichia coli K88 attached to wells (log colony-forming units (cfu) per well) coated with the natural ileal mucus after pre-incubation with the different fractions obtained after the digestion process of (A) wheat bran (WB) and (B) locust bean (LB) in the blocking test. WEM, waterextractable material after enzymatic digestion ( $\alpha$-amylase, protease and amyloglucosidase) and dialysis; AED1, fraction obtained after the first alkali treatment of the cellulosic residue; AED2, fraction obtained after the second alkali treatment. The lower the log cfu counts, the higher the adhesion-blocking ability. Values are means, with their standard errors represented by vertical bars. ${ }^{\mathrm{a}, \mathrm{b}, \mathrm{c}}$ Mean values with unlike letters were significantly different between the fractions $(P<0 \cdot 05)$. Data were obtained from the experiments carried out in triplicate in two independent assays.

to block the adhesion of ETEC K88 to the intestinal mucus could be due to the digestion process carried out with $\alpha$-amylase, protease and amyloglucosidase enzymes, which probably may have broken the functional structure of a putative glycoprotein or protein responsible for the recognition of ETEC K88 fimbriae. In this sense, the involvement of a glycoprotein or a complex of proteins deriving from WB could be the reason for the specific binding phenomenon. This possibility is no wonder, because some reports have suggested the ability of protein fractions from plant-derived compounds to act as anti-adhesive substrates ${ }^{(36,37)}$. It could also suggest that the ability of WB to adhere to ETEC K88 can be reduced along the gastrointestinal tract through digesta. However, this hypothesis merits further in vivo studies.

\section{Locust bean}

The LB used in the present study comprised the milled mixture of carob pods and part of their seeds. This FI is highly rich in galactomannans, a neutral polysaccharide consisting of a $\beta$-( $1 \rightarrow 4)$-mannan backbone to which single D-galactopyranosyl residues are attached via $\alpha-(1 \rightarrow 6)$ linkages. Apart from the wide range of technological applications as feed additives ${ }^{(38)}$, galactomannans are also interesting because it has been reported that mannan residues are able to inhibit fimbrial adhesins of enteropathogens such as E. coli and Salmonella ${ }^{(39)}$.

The LB extract reduced the adhesion of ETEC K88 to the mucus in a similar way to WB; however, LB did not exhibit any ability to adhere to the pathogen. The linear and quadratic contrasts were observed significantly in the dose-response assay. Previous studies using plant products rich in galactomannans have demonstrated anti-adhesive properties against many pathogens. Strong inhibition of Pseudomonas aeruginosa by LB, guar galactomannans and acacia gum has been observed $^{(13)}$. In the same line, Hermes et al. ${ }^{(14)}$ showed the anti-adhesive response against ETEC K88 in porcine intestinal epithelial cells using LB, whereas, more recently, Badia et al. ${ }^{(40)}$ have reported the anti-adhesive effects of a highly rich $\beta$-galactomannan purified from the carob bean gum against
Salmonella. The chemical organisation and ramification of sugars of these leguminous plants seem to be essential for the disruption of pathogen receptor recognition ${ }^{(41)}$

It is intriguing why the positive effects observed were associated with LB, but not with LG or with the purified D-mannose sugar. The LB used in the present study is from a mixture of seeds and pods where the percentage of endosperm per one pod is about $6 \%{ }^{(42)}$, while LG is processed from seed milling, where $52 \%$ of the weight of the seed corresponds to the endosperm (where galactomannans are also present). Therefore, galactomannan content is much lower in LB than in LG. On this basis, LB composition is more heterogeneous. The locust pod is especially rich in insoluble dietary fibre and diverse polyphenolic compounds $(83 \mathrm{mg} / \mathrm{kg})^{(43)}$. Phenolic compounds have been reported to be involved in the blockage of bacterial adhesion ${ }^{(44-46)}$ and specifically in the recognition of ETEC $\mathrm{K} 88^{(37)}$. Thus, it could be hypothesised that the antiadhesive response exhibited by LB could have been mediated by the phenolic compounds interfering with $\mathrm{F} 4$ recognition rather than by galactomannans. Liu et al. ${ }^{(47)}$ demonstrated that proanthocyanidins obtained from cranberry juice can compress the $P$ fimbriae of uropathogenic $E$. coli and interfere with bacterial adhesion.

With regard to the fractions obtained from LB, the first fraction after enzymatic digestion, WEM, exhibited the same anti-adhesive capacity as did the sonicated extract, whereas the dialysed products did not. This result could suggest that the digestion process did not modify the responsible moiety. Based on this point of view, soluble galactomannans and/or phenolic compounds could be responsible for the recognition of the type 1 fimbriated $E$. coli ${ }^{(13,39)}$, as none of the three enzymes included in the digestion process were expected to break down their linkages.

\section{Exopolysaccharides}

EPS are long-chain polysaccharides consisting of branched, repeating units of sugars or sugar derivatives, mainly glucose, galactose and rhamnose, in different ratios ${ }^{(48)}$. They are exocellular molecules excreted during bacterial growth. EPS from Lactobacillus and Bifidobacteria have been shown to 
play an important role in the formation of biofilms ${ }^{(49)}$. The product tested in this work was obtained from the natural fermentation process of green olives in which Lactobacillus pentosus and yeasts have had a relevant role ${ }^{(50,51)}$. The results demonstrated the ability of ETEC K88 to adhere to this substrate, but it was not able to promote significant reductions of the adhesion of ETEC K88 to the intestinal mucus. It seems as if the adhesion of fimbria F4 to EPS would not be enough to interfere with the blocking process. We can hypothesise that bacterial EPS, as complex chemical structures, could offer a variable number of complementary molecules to bacterial and mucus lectins. If EPS could attach not only to fimbria F4 but also to other molecular structures in the mucus, EPS could even favour the attachment of the bacteria. In this regard, the potential of different EPS to adhere to probiotics or enteropathogens in the mucus have been described previously by other authors ${ }^{(16,17)}$. The lack of ability, as had been found by us, to reduce the attachment to the mucus does not fully exclude the potential of EPS to interfere with the adhesion of bacteria to the epithelial cells. The adhesion to epithelial cells is a requisite for infection; nevertheless, adhesion to the mucus can be considered as a way to maintain bacteria far from the epithelium borderline ${ }^{(52)}$. In vitro studies carried out with epithelial cells could confirm this hypothesis. In this regard, different works describing how EPS can reduce the adhesion of $E$. coli to Caco-2 cells ${ }^{(53)}$ and to porcine erythrocytes can be found ${ }^{(54)}$.

\section{Other ingredients}

All the ingredients used in the present study were chosen based on previously reported properties interfering with bacterial adhesion and/or on their chemical composition, particularly regarding a carbohydrate profile. However, several of them exhibited limited or non-significant effects in the present study.

LG and guar gum seemed to be of interest for testing because of their reported high galactomannan content ${ }^{(55)}$ and due to the reduction of bacterial numbers observed in the digesta of piglets ${ }^{(56)}$. However, the present results did not indicate any effect on adhesion or blocking activity. Soyabean meal oligosaccharides, mainly composed of fructose, galactose and glucose, have been reported to promote the competitive exclusion of potential pathogens ${ }^{(57)}$. Studies carried out by van der Meulen et al. ${ }^{(58)}$ have demonstrated the effects of different legume seeds and their hull fractions as preventives of ETEC K88 colonisation. Nonetheless, the present in vitro tests were not able to evaluate competitive exclusion effects; rather, they only evaluated the pathogenmucus interaction.

SBP is an important by-product of the sugar extraction industry rich in heterogeneous pectins such as rhamnogalacturonan, among others ${ }^{(59)}$. The inclusion of SBP in swine diets has been shown to modify the intestinal microbiota and the fermentative pattern by a bifidogenic effect ${ }^{(33)}$ related to the presence of long-chain arabino-oligosaccharides ${ }^{(60)}$. However, SBP did not exhibit adhesive and/or anti-adhesive effects in these in vitro microtitration-based models.
With regard to CRA, MOS, A. oryzae, fructo-oligosaccharides and inulin, no significant effect either in the adhesion test or in the BT was found, despite the previous evidence found in the literature. Cranberry extract is known to prevent human urinary tract infections by disrupting bacterial ligand-uroepithelial receptors and by changing the physico-chemical surface properties of $E$. coli ${ }^{(47)}$. The MOS is an extract from yeast cell walls that has already been shown to exhibit beneficial effects in piglets by reducing the jejunal number of enterobacteria ${ }^{(61)}$ and by reducing faecal coliform numbers after an ETEC K88 challenge ${ }^{(62)}$. MOS had been described by many authors as being able to specifically interfere with the adhesion of pathogens, such as E. coli ${ }^{(18,19)}$ and Salmonella ${ }^{(63)}$, to the intestine. Similar properties have been described for $A$. oryzae ${ }^{(64)}$. The fermented extract from $A$. oryzae also presents a very unique composition based upon primary fermentation containing high amounts of mannoproteins. Even though the anti-adhesive properties of oligosaccharides such as fructo-oligosaccharides and inulin against bacterial pathogens have been proposed ${ }^{(65)}$, no interference was found against ETEC K88 in the present in vitro study.

In summary, the use of two microtitration-based in vitro models has allowed for the identification of certain FI to specifically adhere to and to inhibit the adhesion ETEC K88 to the mucus. However, it should be stated that the absence of effects observed in the present study for some of the tested ingredients does not completely exclude the possibility that they could have a potential role in intestinal colibacillosis through other mechanisms not evaluated by the present in vitro models, such as the blockage of adhesion to the epithelial cells. Among all the FI screened in the present study, WB, CGMP and LB exhibited anti-adhesive properties against ETEC K88, representing the most promising FI. The results obtained from the fractionation of WB suggest that the responsible molecule may be a glycoprotein or a complex of different proteins that specifically recognises ETEC K88. By contrast, galactomannans or phenolic compounds could be the responsible antiadhesive in LB. Despite the fact that molecules responsible for the antiadhesive response have not been elucidated, the positive effects demonstrated in the present study make them candidates suitable to be included in the diet of piglets with supported functional activity. Even though the purpose of the present study was to evaluate the anti-adhesive properties of 'intact' natural products, it should be noted that some of these FI could be digested in the small intestine of piglets ${ }^{(66,67)}$ and then activities may be modified. In this sense, further studies are needed to check their anti-adhesive activity throughout the intestinal tract as well as their efficacy to prevent the attachment of pathogens under field conditions.

\section{Acknowledgements}

The authors thank Professor Calvo of the Universitat Autònoma de Barcelona for her kind assistance throughout the whole experiment. The authors also acknowledge the companies that kindly provided the FI used in both in vitro screenings: Armegol Hermanos S.A, Arla Foods, Cran Max and Molimen, S.L. This manuscript was proofread by Mr Chuck Simmons, a 
native English-speaking instructor of English of the Universitat Autònoma de Barcelona.

The present study was supported by the public research project of the Spanish Ministry of Education and Science (Project AGL 2009-07328). The Spanish Ministry of Education and Science had no role in the design and analysis of the study or in the writing of this article.

All the co-authors participated in the research and the writing of this article equally.

None of the authors has any conflicts of interest.

\section{References}

1. Fairbrother JM, Nadeau E \& Gyles CL (2005) Escherichia coli in postweaning diarrhea in pigs: an update on bacterial types, pathogenesis, and prevention strategies. Anim Health Res Rev 6, 17-39.

2. Zhang W, Zhao M, Ruesch L, et al. (2007) Prevalence of virulence genes in Escherichia coli strains recently isolated from young pigs with diarrhea in the US. Vet Microbiol 123, $145-152$.

3. Jensen GM, Frydendahl K, Svendsen O, et al. (2006) Experimental infection with Escherichia coli O149:F4ac in weaned piglets. Vet Microbiol 115, 243-249.

4. Erume J, Berberov EM, Kachman SD, et al. (2008) Comparison of the contributions of heat-labile enterotoxin and heat-stable enterotoxin $\mathrm{b}$ to the virulence of enterotoxigenic Escherichia coli in F4ac receptor-positive young pigs. Infect Immun 76, 3141-3149.

5. Hermes RG, Molist F, Francisco Perez J, et al. (2012) Casein glycomacropeptide in the diet may reduce Escherichia coli attachment to the intestinal mucosa and increase the intestinal lactobacilli of early weaned piglets after an enterotoxigenic E. coli K88 challenge. Br J Nutr 109, 1001-1012.

6. Jin LZ \& Zhao X (2000) Intestinal receptors for adhesive fimbriae of enterotoxigenic Escherichia coli (ETEC) K88 in swine - a review. Appl Microbiol Biotechnol 54, 311-318.

7. Erickson AK, Baker DR, Bosworth BT, et al. (1994) Characterization of porcine intestinal receptors for the K88ac fimbrial adhesin of Escherichia coli as mucin-type sialoglycoproteins. Infect Immun 62, 5404-5410.

8. Shoaf-Sweeney KD \& Hutkins RW (2009) Adherence, antiadherence, and oligosaccharides preventing pathogens from sticking to the host. Adv Food Nutr Res 55, 101-161.

9. Lane JA, Mehra RK, Carrington SD, et al. (2010) The food glycome: a source of protection against pathogen colonization in the gastrointestinal tract. Int J Food Microbiol 142, $1-13$.

10. Ofek I, Hasty DL \& Sharon N (2003) Anti-adhesion therapy of bacterial diseases: prospects and problems. FEMS Immunol Med Microbiol 38, 181-191.

11. Roubos-van den Hil PJ, Nout MJ, Beumer RR, et al. (2009) Fermented soya bean (tempe) extracts reduce adhesion of enterotoxigenic Escherichia coli to intestinal epithelial cells. J Appl Microbiol 106, 1013-1021.

12. Roubos-van den Hil PJ, Dalmas E, Nout MJ, et al. (2010) Soya bean tempe extracts show antibacterial activity against Bacillus cereus cells and spores. J Appl Microbiol 109, 137-145.

13. Zinger-Yosovich KD \& Gilboa-Garber N (2009) Blocking of Pseudomonas aeruginosa and Ralstonia solanacearum lectins by plant and microbial branched polysaccharides used as food additives. J Agric Food Chem 57, 6908-6913.

14. Hermes RG, Manzanilla EG, Martin-Orue SM, et al. (2011) Influence of dietary ingredients on in vitro inflammatory response of intestinal porcine epithelial cells challenged by an enterotoxigenic Escherichia coli (K88). Comp Immunol Microbiol Infect Dis 34, 479-488.

15. Windisch W, Schedle K, Plitzner C, et al. (2008) Use of phytogenic products as feed additives for swine and poultry. J Anim Sci 86, Suppl. 14, E140-E148.

16. Ruas-Madiedo P, Gueimonde $M$, de los Reyes-Gavilan CG, et al. (2006) Short Communication: effect of exopolysaccharide isolated from "villi" on the adhesion of probiotics and pathogens to intestinal mucus. J Dairy Sci 89, 2355-2358.

17. Ruas-Madiedo P, Gueimonde M, Margolles A, et al. (2006) Exopolysaccharides produced by probiotic strains modify the adhesion of probiotics and enteropathogens to human intestinal mucus. J Food Prot 69, 2011-2015.

18. Baurhoo B, Phillip L \& Ruiz-Feria CA (2007) Effects of purified lignin and mannan oligosaccharides on intestinal integrity and microbial populations in the ceca and litter of broiler chickens. Poult Sci 86, 1070-1078.

19. Baurhoo B, Letellier A, Zhao X, et al. (2007) Cecal populations of lactobacilli and bifidobacteria and Escherichia coli populations after in vivo Escherichia coli challenge in birds fed diets with purified lignin or mannanoligosaccharides. Poult Sci 86, 2509-2516.

20. Fang L, Gan Z \& Marquardt RR (2000) Isolation, affinity purification, and identification of piglet small intestine mucosa receptor for enterotoxigenic Escherichia coli $\mathrm{k} 88 \mathrm{ac}+$ fimbriae. Infect Immun 68, 564-569.

21. Becker PM, Galletti S, Roubos-van den Hil PJ, et al. (2007) Validation of growth as measurand for bacterial adhesion to food and feed ingredients. I Appl Microbiol 103, 2686-2696.

22. Maes C \& Delcour JA (2002) Structural characterisation of water-extractable and water-unextractable arabinoxylans in wheat bran. J Cereal Sci 35, 315-326.

23. Blanco M, Blanco JE, Gonzalez EA, et al. (1997) Genes coding for enterotoxins and verotoxins in porcine Escherichia coli strains belonging to different O:K:H serotypes: relationship with toxic phenotypes. J Clin Microbiol 35, 2958-2963.

24. Snellings NJ, Tall BD \& Venkatesan MM (1997) Characterization of Shigella type 1 fimbriae: expression, FimA sequence, and phase variation. Infect Immun 65, 2462-2467.

25. Brody EP (2000) Biological activities of bovine glycomacropeptide. Br J Nutr 84, Suppl. 1, S39-S46.

26. Nakajima K, Tamura N, Kobayashi-Hattori K, et al. (2005) Prevention of intestinal infection by glycomacropeptide. Biosci Biotechnol Biochem 69, 2294-2301.

27. Malkoski M, Dashper SG, O’Brien-Simpson NM, et al. (2001) Kappacin, a novel antibacterial peptide from bovine milk. Antimicrob Agents Chemother 45, 2309-2315.

28. Grange PA, Mouricout MA, Levery SB, et al. (2002) Evaluation of receptor binding specificity of Escherichia coli K88 (F4) fimbrial adhesin variants using porcine serum transferrin and glycosphingolipids as model receptors. Infect Immun 70, 2336-2343.

29. Rhoades JR, Gibson GR, Formentin K, et al. (2005) Caseinoglycomacropeptide inhibits adhesion of pathogenic Escherichia coli strains to human cells in culture. J Dairy Sci 88, 3455-3459.

30. Espinoza-Castañeda M, de la Escosura-Muniz A, GonzalezOrtiz G, et al. (2013) Casein modified gold nanoparticles for future theranostic applications. Biosens Bioelectron $\mathbf{4 0}$, 271-276.

31. Palmarola-Adrados B, Choteborska P, Galbe M, et al. (2005) Ethanol production from non-starch carbohydrates of wheat bran. Bioresour Technol 96, 843-850. 
32. Mohsin-Javed M, Zahoor S, Shafaat S, et al. (2012) Wheat bran as a brown gold: nutritious value and its biotechnological applications. Afr J Microbiol Res 6, 724-733.

33. Hermes RG, Molist F, Ywazaki M, et al. (2009) Effect of dietary level of protein and fiber on the productive performance and health status of piglets. J Anim Sci 87, 3569-3577.

34. Molist F, Gómez de Segura A, Pérez J, et al. (2009) Effect of wheat bran on the health and performance of weaned pigs challenged with Escherichia coli $\mathrm{K}^{+} 8^{+}$. Livest Sci 133, 214-217.

35. Molist F, Hermes RG, de Segura AG, et al. (2011) Effect and interaction between wheat bran and zinc oxide on productive performance and intestinal health in post-weaning piglets. Br J Nutr 105, 1592-1600.

36. Lengsfeld C, Titgemeyer F, Faller G, et al. (2004) Glycosylated compounds from okra inhibit adhesion of Helicobacter pylori to human gastric mucosa. J Agric Food Chem 52, 1495-1503.

37. Wittschier N, Lengsfeld C, Vorthems S, et al. (2007) Large molecules as anti-adhesive compounds against pathogens. J Pharm Pharmacol 59, 777-786.

38. Rinaudo M (2008) Main properties and current applications of some polysaccharides as biomaterials. Polym Int 57, $397-430$.

39. Swanson KS, Grieshop CM, Flickinger EA, et al. (2002) Supplemental fructooligosaccharides and mannanoligosaccharides influence immune function, ileal and total tract nutrient digestibilities, microbial populations and concentrations of protein catabolites in the large bowel of dogs. J Nutr 132, 980-989.

40. Badia R, Brufau MT, Guerrero-Zamora AM, et al. (2012) $\beta$-Galactomannan and Saccharomyces cerevisiae var. boulardii modulate the immune response against Salmonella enterica serovar Typhimurium in porcine intestinal epithelial and dendritic cells. Clin Vaccine Immunol 19, 368-376.

41. Badia R, Zanello G, Chevaleyre C, et al. (2012) Effect of Saccharomyces cerevisiae var. Boulardii and beta-galactomannan oligosaccharide on porcine intestinal epithelial and dendritic cells challenged in vitro with Escherichia coli F4 (K88). Vet Res $\mathbf{4 3}, 4$.

42. Albanell E, Caja G \& Plaixats J (1996) Characterization of carob fruits (Ceratonia siliqua L.), cultivated in Spain for agroindustrial use. Int Tree Crops J 9, 1-9.

43. Papagiannopoulos M, Wollseifen HR, Mellenthin A, et al. (2004) Identification and quantification of polyphenols in carob fruits (Ceratonia siliqua L.) and derived products by HPLC-UV-ESI/MSn. J Agric Food Chem 52, 3784-3791.

44. Huttunen S, Toivanen M, Arkko S, et al. (2011) Inhibition activity of wild berry juice fractions against Streptococcus pneumoniae binding to human bronchial cells. Phytother Res 25, 122-127.

45. Kurek A, Grudniak AM, Kraczkiewicz-Dowjat A, et al. (2011) New antibacterial therapeutics and strategies. Pol J Microbiol 60, 3-12

46. Riihinen K, Ryynanen A, Toivanen M, et al. (2011) Antiaggregation potential of berry fractions against pairs of Streptococcus mutans with Fusobacterium nucleatum or Actinomyces naeslundii. Phytother Res 25, 81-87.

47. Liu Y, Gallardo-Moreno AM, Pinzon-Arango PA, et al. (2008) Cranberry changes the physicochemical surface properties of E. coli and adhesion with uroepithelial cells. Colloids Surf $B$ Biointerfaces 65, 35-42.

48. Welman AD \& Maddox IS (2003) Exopolysaccharides from lactic acid bacteria: perspectives and challenges. Trends Biotechnol 21, 269-274.

49. Lebeer S, Verhoeven TL, Perea Velez M, et al. (2007) Impact of environmental and genetic factors on biofilm formation by the probiotic strain Lactobacillus rhamnosus GG. Appl Environ Microbiol 73, 6768-6775.

50. Garrido-Fernández A, Fernández-Díaz M \& Adams R (1997) Table Olives: Production and Processing. London: Chapman \& Hall.

51. Arroyo-López F, Querol A, Bautista-Gallego J, et al. (2008) Role of yeasts in table olive production. Int J Food Microbiol 128, 189-196.

52. Variyam EP (2007) Luminal host-defense mechanisms against invasive amebiasis. Trends Parasitol 23, 108-111.

53. Alp G, Aslim B, Suludere Z, et al. (2010) The role of hemagglutination and effect of exopolysaccharide production on bifidobacteria adhesion to Caco-2 cells in vitro. Microbiol Immunol 54, 658-665.

54. Wang Y, Gänzle M \& Schwab C (2010) Exopolysaccharide synthesized by Lactobacillus reuteri decreases the ability of enterotoxigenic Escherichia coli to bind to porcine erythrocytes. Appl Environ Microbiol 76, 4863-4866.

55. Mathur N (2012) Industrial Galactomannan Polysaccharides. Boca Raton, FL: CRC Press.

56. Van Nevel CJ, Decuypere JA, Dierick NA, et al. (2005) Incorporation of galactomannans in the diet of newly weaned piglets: effect on bacteriological and some morphological characteristics of the small intestine. Arch Anim Nutr 59, 123-138.

57. Qiang X, YongLie C \& QianBing W (2009) Health benefit application of functional oligosaccharides. Carbohydr Polym 77, 435-441.

58. van der Meulen J, Panneman H \& Jansman A (2010) Effect of pea, pea hulls, faba beans and faba bean hulls on the ileal microbial composition in weaned piglets. Livest Sci 133, 135-137.

59. Guillon F \& Thibault J (1983) Methylation analysis and mild acid hydrolysis of the "hairy" fragments of sugar beet pectins. Carbohydr Res 190, 85-96.

60. Holck J, Lorentzen A, Vigsnaes LK, et al. (2011) Feruloylated and nonferuloylated arabino-oligosaccharides from sugar beet pectin selectively stimulate the growth of Bifidobacterium spp. in human fecal in vitro fermentations. J Agric Food Chem 59, 6511-6519.

61. Castillo M, Martin-Orue SM, Taylor-Pickard JA, et al. (2008) Use of mannanoligosaccharides and zinc chelate as growth promoters and diarrhea preventative in weaning pigs: effects on microbiota and gut function. J Anim Sci 86, 94-101.

62. White L, Newman M, Cromwell G, et al. (2002) Brewers dried yeast as a source of mannan oligosaccharides for weanling pigs. J Anim Sci 80, 2619-2628.

63. Fernández F, Hinton M \& van Gils B (2000) Evaluation of the effect of mannanoligosaccharides on the competitive exclusion of Salmonella enteritidis colonization in broiler chicks. Avian Pathol 29, 575-581.

64. Becker P \& Galleti S (2008) Food and feed components for gut health-promoting adhesion of E. coli and Salmonella enterica. J Sci Food Agric 88, 2026-2035.

65. Gibson GR, McCartney AL \& Rastall RA (2005) Prebiotics and resistance to gastrointestinal infections. Br J Nutr 93, Suppl. 1, S31-S34.

66. Kiarie E, Nyachoti CM, Slominski BA, et al. (2007) Growth performance, gastrointestinal microbial activity, and nutrient digestibility in early-weaned pigs fed diets containing flaxseed and carbohydrase enzyme. J Anim Sci 85, 2982-2993.

67. Gdala J, Johansen HN, Bach Knudsen KE, et al. (1997) The digestibility of carbohydrates, protein and fat in the small and large intestine of piglets fed non-supplemented and enzyme supplemented diets. Anim Feed Sci Tech 65, 15-33. 